\title{
AN OVERVIEW OF EXPERIMENTAL AUTOGENOUS VEIN GRAFTS
}

\author{
John K. Me Geachie, Marc Tennant \\ Department of Anatomy and Human Biology \\ The University of Western Australia
}

\begin{abstract}
- Examination of the changes in experimental autogenous vein grafts has presented some important results for both human surgical grafts and also for atherosclerosis. We have developed a microsurgical grafting model in the rat, by anastomosing $4 \mathrm{~mm}$ of the iliolumbar vein into the iliac artery. The primary cellular response involves the proliferation and migration ofendothelium and smooth muscle cells from the adjacent artery. The majority of this activity is complete within the first 4 weeks after grafting. This development of the new cells in the vein graft is described as intimal (or neo-intimal) hyperplasia. The revascularisation by the vasa vasorum and the re-establishment of sympathetic reinnervation of the graft have both been quantitated in detail. In addition, we are now examingfactors that influence the intimal hyperplastic response, specifically nicotine, cholesterol and high blood pressure. These factors, as well as being of clinical importance, also give an indication of the pathogenesis of intimal hyperplasia. In this article we briefly review the work that we have completed over the last 15years and its relevance to the experimental and clinical research literature on intimal hyperplasia.
\end{abstract}

\section{INTRODUCTION}

- The number of patients presenting with disorders of the vascular system (especially occlusive conditions) is increasing(l). The advent of modern surgical techniques, particularly the use of microsurgery and the availability of numerous vascular prostheses, have enhanced the vascular surgeon's ability to "bridge" arterial defects, both occlusive and traumatic.

The autogenous vein segment is still by far the most commonly used graft material. By as long ago as 1975 it was estimated that in the USA alone 100000 aortocoronary bypasses were being performed annually(l). Various other materials have also been used as by-pass conduits. Synthetic prostheses were initially used by Voorhees in 1952(2) and subsequently numerous synthetic materials have been tried $(2,3,4)$.

In modern western society atherosclerosis of the coronary arteries is present more commonly than ever before(5). Atherosclerosis is characterised by a focal thickening of the vessel wall, specifically the intima(6). This thickening consists of accumulations of fat, layers of collagen-like fibres, and a number of cell populations $(7,8)$. The use of vein grafts to bypass atherosclerotic changes in coronary arteries has been developed over the lastSOyears(1).

\section{THE VEIH GRAFT MODEL; A HISTORICAL PERSPECTIVE}

- Our initial research objective was to develop an experimental model for testing the antigenicity of venous tissue, when placed into arteries as vein-to-artery grafts. At that time (mid 1970s) the coronary artery by-pass operation for relief of myocardial ischaemia had just become very successful and popular. This procedure involved inserting segments of saphenous vein from the leg into coronary arteries to by-pass seriously narrowed (stenosed) vessels. These were "autografts", in that vein segments were taken from the same individual who required the graft, thus avoiding immune response complications. However, some individuals who had grafts in place for a few years had subsequently developed stenosis of the grafts and it was necessary to explore the possibility of using donor vein grafts from other individuals (allografts). Our first task was to develop an experimental model in which to determine the antigenicity of vein grafts. 
We subsequently developed a precise experimental model by placing a small, $4 \mathrm{~mm}$, segment of the iliolumbar vein into the iliac artery in rats. Both vessels were $1 \mathrm{~mm}$ in diameter and although the microsurgery was technically difficult, the size match was excellent. Eight micro-sutures of 10.0 Ethilon were inserted at each anastomosis and we developed a "four handed" reliable technique for ensuring even tension and spacing between sutures. The patiency rate for these grafts was 80-90\% which was excellent for such difficult procedures $(9,10)$.

\section{HISTOGEHESIS OF VEIH GRAFT TISSUES}

- We conducted detailed histological examinations of our experimental grafts from one to 18 weeks after insertion and found that nearly all of the original graft tissue was phagocytosed by 2 weeks after surgery; this was replaced by regenerated tissues, presumably from the host. The vein graft wall at operation was only 50-80 urn thick and consisted mostly of collagen, with very few cells. Thus, macrophages removed most of this tissue rapidly after surgery and a new vessel regenerated (11). This regenerative response, whereby a new "pseudo-artery" with endothelium, smooth muscle and elastin had developed, occured within 4 weeks $(12,13)$.

One striking feature of these vein grafts was the development of the intima, a layer which was structurally analogous to the media in an artery. In an artery the intima consists of a layer of endothelial cells, a subendothelial layer of amorphous material and an inner elastic lamina. The media has concentrations of smooth muscle cells (SMC) interspersed with elastin; the adventita has connective tissue and contains the nerves and nutrient blood vessels (vasa vasorum).

Contrastingly, vein grafts contain endothelium plus smooth muscle and elastin (equivalent to an arterial media) that develops on the inner (lumenal) aspect of the "old" inner elastic lamina of the original vein graft segment. This "old" lamina is 1 urn thick and survives in the vein graft for many months after insertion. It provided a most useful marker for the vein graft intima (14). Other studies have shown that during the initial month after graft placement, histological changes are associated with inflammation and regeneration of the endothelium (15).

Once the endothelial lining had been established, over a carpet of platelets lying directly upon the raw graft surface of the original elastic lamina (12), by 15 days after surgery, SMC started to migrate into the elastic lamina and the overlying endothelium $(16,17)$.

The origin of SMC found within the graft intima after this initial regenerative period is not clear (14). Using radioactive thymidine labelling techniques, it has been shown that proliferation of SMC reduced to background levels three months after graft placement (15). Histologi- cally, intimal SMC appear similar to those of the media, with many in a "transitionary" phenotypic state (18). This would explain Fuchs et al, (1978) findings of booth fibroblasts and SMC within the media (19). These modified SMC were oriented longitudinally rather than in the predominantly circular arrangement which is typical for vein media (18). Between the cells of the intima were collagen fibres (arranged longitudinally), and rarely some elastin (20). Other researches have demonstrated "transformation" of myocytes to fibroblast-like cells occuring in association with the deterioration of other SMC within the vascular wall of grafts. A reduction inmyofilaments and an increase in rough endoplasmic reticulum in SMC signalled the change in function from contractile to secretory (21).

The connective tissue content of the hyperplastic intima exhibits a specific pattern: remaining SMC become separated by collagen, elastin, and fibro-matrix into a layered functional architecture. The myofibroblasts were mainly associated with regions of active intimal hyperplasia (22). The morphology of intimal hyperplasia is similar in various vascular graft types (human vein, bovine vein, Dacron) (23).

In human subjects with aorto-coronary bypasses intimal hyperplasia occurs at varying rates $(24,25)$. Intimal hyperplasia may reduce lumenal diameter continuously until stenosis occurs, or reduce the diameter to a certain level and remain unchanged (24). The clinical consequences are obviously very serious. Very recent work from our group, using pulse labelling of tritiated thymidine, has shown conclusively that the SMC are derived from the media of the adjacent artery (Figure 1) (26).

\section{REGENERATING CELL POPULATIONS}

- Another major direction of this research on the histogenesis of intimal hyperplasia has been to quantitate the intracellular changes that occur in regenerating vascular graft tissues.

\section{Smooth muscle cells.}

A combination of electron microscopy and morphometry was used to show that SMC in the first few weeks after grafting change their intracellular components to a "synthetic" functional type, where they synthesize cytoplasmic and extracellular matrix components. The contractile filaments are relatively sparse in these cells as they build up other cytoplasmic elements. Later, when these cells have proliferated, migrated and matured they become filled with contractile filaments. A great deal of research in vitro has been devoted to characterising these so-called "phenotypes" of smooth muscle: synthetic or contractile (17). This research has been directed towards understanding SMC changes in vascular pathology, particularly atherosclerosis. Our research in the vein grafts 

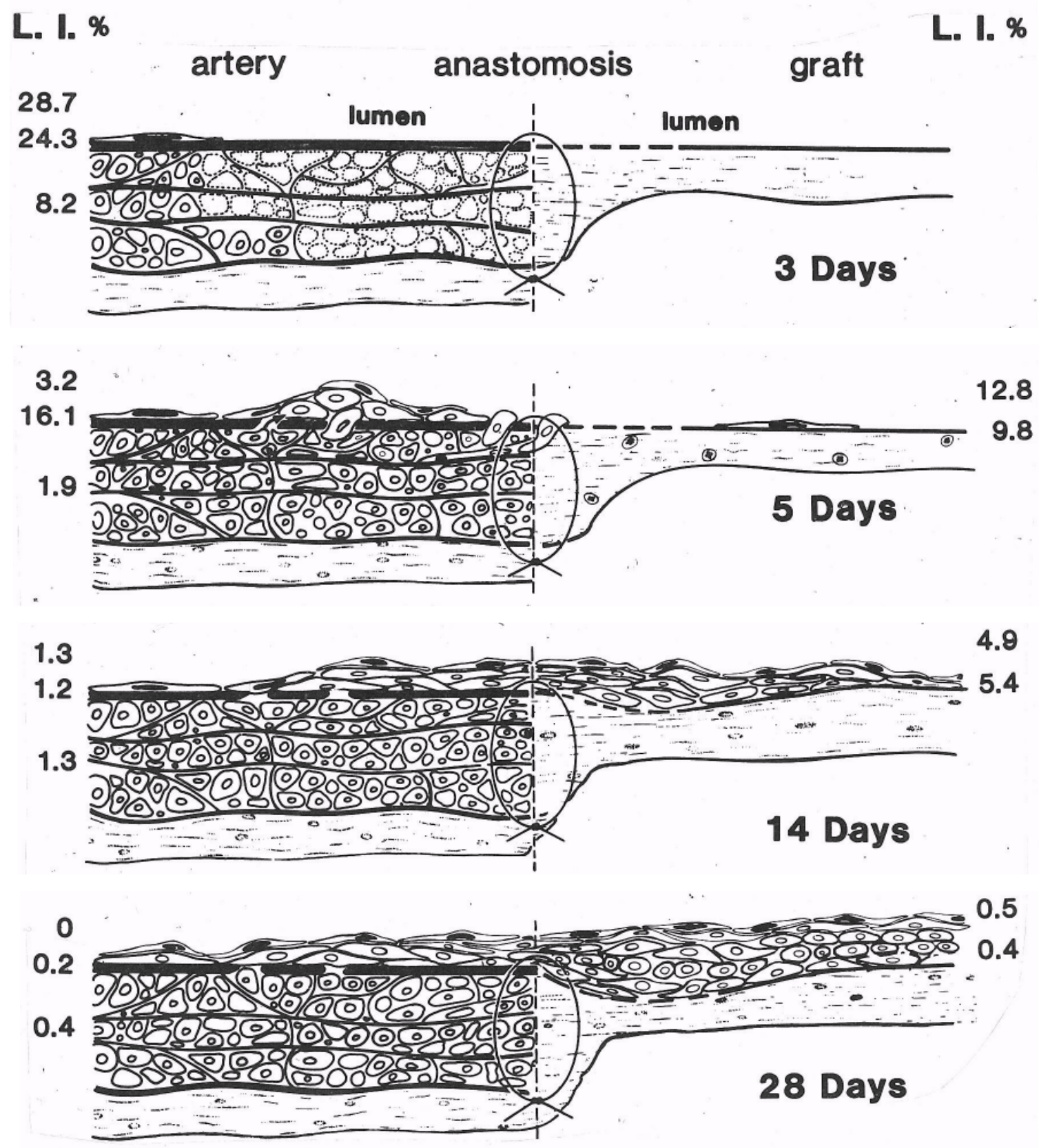

FIGURE LA diagramatic representation of cellular changes in vein grafts over 28 days after insertion. Labelling indices for tritiatedthymidine incoportation and autoradiographic labelling are shown at the edges of the diagrams.

has shown how adaptable SMC are in vivo and how quickly they can modulate their phenotype.

\section{Endothelial cells.}

Scanning electron microscopy (SEM) was used in another series of experimental vein grafts to investigate the growth and maturation of endothelial cells. Actually they were derived from the adjacent artery, by mitotic division, which was maximal at 3 days after grafting. A sheet of endothelium then migrated across the anastomosis and covered the $4 \mathrm{~mm}$ of the graft by 15 days after grafting. Maturation of the endothelial cells, as evidenced by growth and development of overlapping tight inter-cellular junctions, was analysed in detail. This is a most important phenomenon because these junctions form permeability 
barriers to macro-molecules which are not normally allowed to escape the blood stream. Junctions were mature by 8 weeks after surgery. This was observed directly by SEM and confirmed experimentally by perfusing the grafted rats with Evan 's Blue Dye (EBD) one hour prior to sacrifice, at the various times after graft insertion. EBD binds to plasma albumin which does not normally penetrate/permeate the intact endothelium. Our data showed a direct correlation between the distribution of EBD staining in the grafts with the maturation of endothelial cell junctions (12).

Recent transmission electron microscopic studies by our group examining endothelial cells regenerating in vein grafts have produced some interesting findings. Endothelial cells in vein grafts have significantly greater proportions of vesicles, mitochondria and rough endoplasmic reticulum when lining grafts (28). Although this should be expected during the early phase of endothelial cell division and migration, it is more difficult to explain why the concentrations of these cytoplasmic elements continued to stay elevated well beyond this initial phase. In fact, they remained high up to at least 52 weeks. We propose that the endothelial cells are permanently changed and as such may produce factors which influence the underlying intimal cellular populations. It is well accepted that endothelial cells produce an extensive array of growth factors, $(29,30)$ many of which have the potential to influence SMC phenorype $(31,32)$. A growth factor which appears to have close links with intimal hyperplasia and atherosclerosis is Platelet Derived Growth Factor (PDGF) (33). This may play an important role in the initiation of intimal hyperplasia.

\section{REVASCULARIZATION OF VEIN GRAFTS}

- This avenue of research was based upon observations from traumatised arteries, where the adventitial covering had been removed, and intimal hyperplasia occured subsequently (35). Was it disruption to the vasa vasorum which initiated intimal hyperplasia, and did this operate in our model? We conducted a detailed quantitative analysis of the regeneration of vasa vasonim in a series of vein grafts. The data showed that vasa vasonim invaded the adventita of the graft very rapidly after the first week. These data were correlated with the development of intimal hyperplasia in these grafts and it was shown that growth of the intima was not associated with any compensatory increase in vasa vasorum $(35,36)$.

The finding that vasa vasorum did not increase with increasing vein graft intimal hyperplasia suggested that as the intima became progressively thicker it might have become more ischaemic35. The rapidity of revascularization we reported in vein grafts has been used in studies on reversed autogenous clinical vein grafts $(37,38)$.

\section{RESERVATION OF VEIN GRAFTS}

- As with the revascularization study there was evidence that sympathetic nerves (catecholaminergic nerves) could stimulate the growth of SMC (the major component of intimal hyperplasia in vein grafts). We hypothesised that regenerating nerves might grow across the vein graft and "attract" SMC from the adjacent artery and/or stimulate their proliferation to build up a population of intimal muscle. To start with we had no evidence that sympathetic nerves regenerate in this situation so the first step was to study the vein grafts for evidence of nerves. It was obvious that sympathetic nerves grew very rapidly across the regenerating vein graft. They were derived from the sympathetic plexus surrounding the neighbouring iliac artery and vein. However, this regenerating nerve plexus was quite different from controls: the grafts' nerve fibres were finer, lacked varicosities and were further from the muscular tissue of the graft than in control arteries $(39,40)$. Although we had established that sympathetic nerve regeneration occurs quite rapidly in our vein grafts, it is not possible to determine whether these regenerated sympathetic nerves stimulated SMC growth and proliferation in the intima.

\section{MANIPULATIONS OF IHTIMAL HYPERPLASIA IN VEIN GRAFTS}

- By the mid 1980s we had studied about 500 small vein grafts and had published a very substantial body of data: on re-endothelialization, revascularization, reinnervation and histogenesis of intimal hyperplasia. Therefore, it was considered that our grafts were an excellent model for investigating the influence of various factors on intimal hyperplasia. Could it be increased or decreased with various agents, drugs or nutritional regimes?

The Influence of Nicotine on Vein Grafts There is abundant clinical evidence to show that people who smoke have an increased risk of developing vascular disease. If such individuals have vascular surgery (such as a vein graft) the probability of the graft failing, due to obliterative intimal hyperplasia is very high. We became very interested in this phenomenon because agents in smoke acting on tissue regeneration in our vein grafts might reveal mechanisms that could operate at the cellular level to induce intimal hyperplasia. Most of the literature to that time concentrated upon both carbon monoxide and nicotine and it became obvious that very little was known about what effect of these agents had on normal blood vessels. This information was essential before any manipulation on vein grafts could be attemped.

Firstly there was evidence (from in vitro) that nicoyears include: J McGeachie, F Prendergast, E Storrie, P Campbell, R Dilley, R Samuels, M Tennant, MZimmerman 


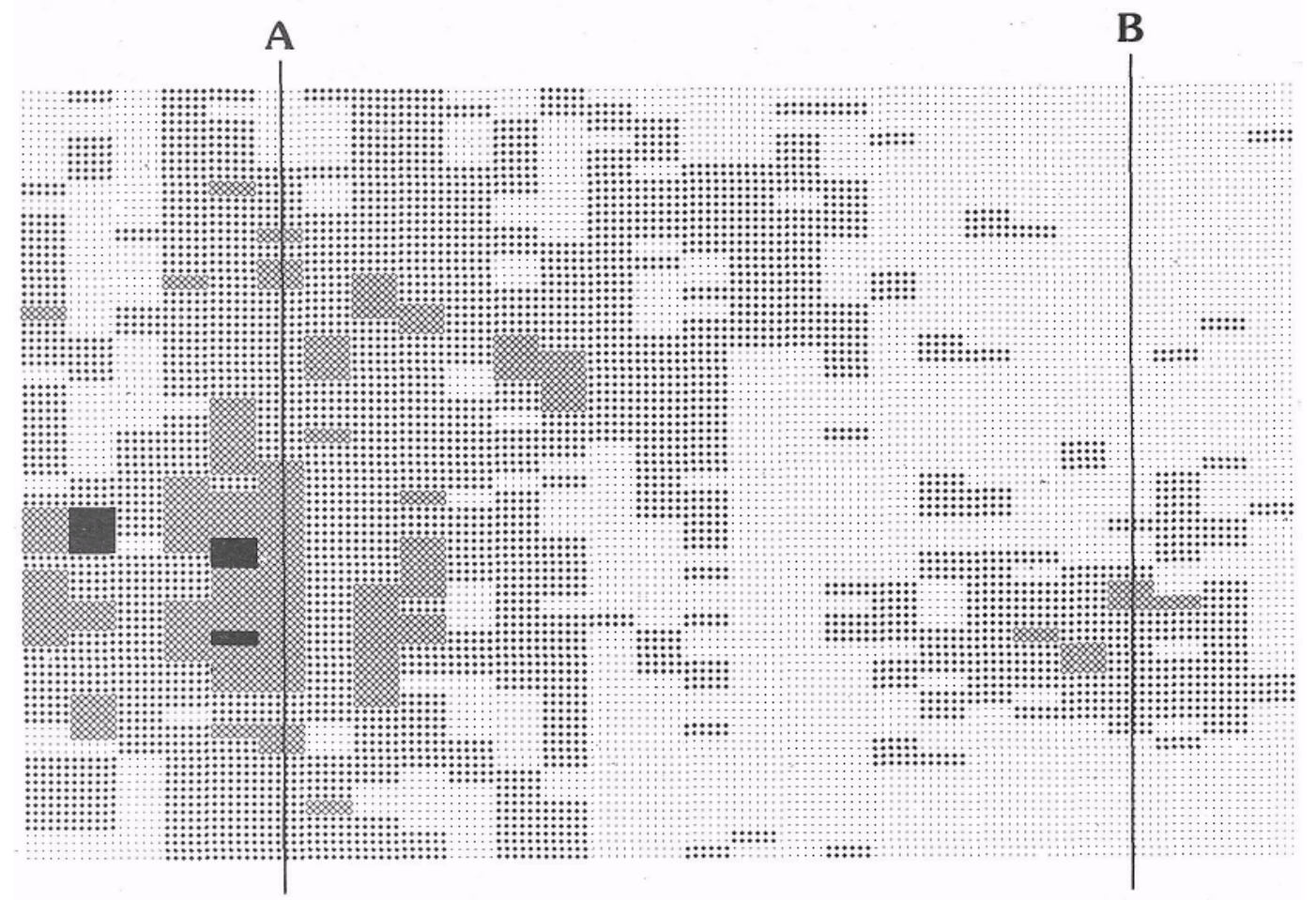

$\begin{array}{lll}\text { Proximal A } & \text { B Distal }\end{array}$

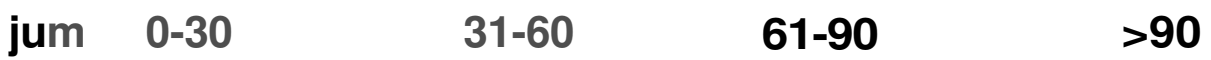
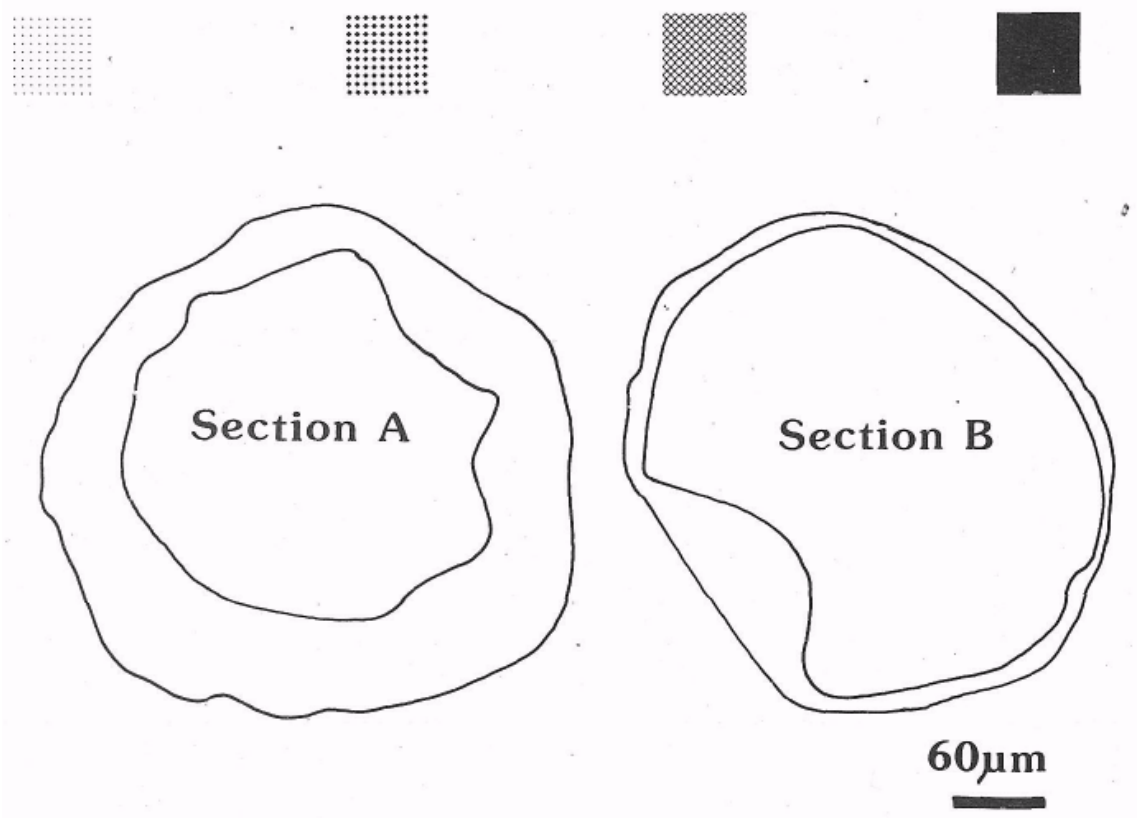

FIGURE 1. A diagramatic representation of the automated computer reconstruction ofintimal thick ness data for a 4 month old graft into a topographical map. 
tine was mitogenic; thus we hypothesised that the increase in mitotic activity (if it did occur in vivo) might render the endothelial surface more permeable to macromolecules in the circulating blood. This in turn might act upon the medial smooth muscle and initiate and promote arterial disease (seen in smokers). Our results showed convincingly that nicotine is mitogenic in arterial endothelium and there was a significantly high level of cell turnover under its influence $(41,42)$. As a consequence, denuded areas of endotheliumoccured and this supported our hypothesis that the permeability of this layer would increase. When investigated further by electron microscopy we found that the intercellular junctions between endothelial cells of nicotine affected rats were substantially less complex, and therefore more permeable, than normal $(43,44,45)$. Furthermore, we confirmed this increased permeability with Horse-Radish Peroxidase, an extra cellular marker.

Our experiments showed convincingly that nicotine increases endothelial cell turnover, creates denuded areas of endothelium and because it opens up the inter-cellular junctions, increases permeability. All these structural and functional features are firm evidence for increased susceptibility to arterial disease.

Based upon this previous work, and upon research on intimal hyperplasia, we hypothesised that nicotine would probably accelerate re-endothelialization of the vein graft (due to its mitogenic effect). Then, because of retarded maturation of endothelial cell junctions, the prolonged increase in permeability would promote much - more intimal hyperplasia than we had seen previously (in "normal" grafts). There is no doubt that nicotine retards endothelial cell maturation, as evidenced by quantitative studies using Evan's Blue Dye staining of regenerating endothelial cells in the vein grafts(46). Moreover, SEM analyses of these same vessels show definite demage to endothelial cell junctions, similar to those we reported in arterial endothelium.

\section{Blood cholesterol levels}

As has been shown extensively in human studies, blood levels of cholesterol are intimately linked with arterial disease. However, the mechanisms involved have not been fully elucidated. It is known that raised cholesterol levels are a potent risk factor for intimal hyperplastic induced restenosis of vein grafts (47). Therefore, we have just completed a series of studies to investigate the effects of raised blood cholesterol on our model. Although the results are still very preliminary it appears that some potentiating effect is occuring even during the early stages following graft placement.

\section{MEASUREMENT OF INTIMAL HYPERPLASIA}

- During all our studies to date, and many other published studies, the quantification of intimal hyperplasia has been difficult to perform with precision $(48,49,50,51)$. For example, we had noticed for many years that focal areas of intimal hyperplasia occur not only in our grafts but in many other vessels (16). Did these focal areas represent regions which could become excessively thickened, or were more prone to degenerative arterial diseases., such as arteriosclerosis or atherosclerosis? Over the last 12-18 months we have developed a whole range of computerbased techniques for the precise quantification of intimal hyperplasia. We can expeditiously make in excess of 5000 thickness measurements on a single graft (52). These are also in a form that allows 3-dimensional reconstruction of a "map" of the intima (Figure 2). Thus we can now quantitate small focal hyperplastic changes using a modern semi-automated approach and detect very early changes in the graft intima.

\section{CONCLUSION}

- Intimal hyperplasia in autogenous vein grafts may initially be a compensatory mechanism for alterations in haemodynamic stresses. The problem is that in some cases this hyperplasia becomes excessive resulting in graft failure by stenosis, with obvious grave clinical consequences. The basis of the numerous studies we have been involved in over the last 15 years has been to examine the mechanism that contribute to graft restenosis. The primary cell population involved in intimal hyperplasia was thought to be SMC, as it makes up the greatest proportion of the intimal cell populations. However, it is becoming more evident that the regulatory roles of endothelial cells and blood-borne cells, specifically monocytes (that become tussue macrophages) are critical $(34,53)$. The numerous growth regulatory substances that these cells produce and their location at the interface between the blood and the vessel wall makes them primary factors in the pathogenesis of intimal hyperplasia. We will be continuing our research efforts in the future towards a better understanding of growth factors, endothelial cells and blood/bloodvessel wall interactions, with the objective of determining their roles in the regulation of SMC division and migration, and consequent influence on both intimal hyperplasia in grafts, and atherosclerosis in general.

\section{ACKNOWLEDGEMENTS}

- Numerous people and funding bodies have being involved in our research. The authors would like to thank: The Nicholas and Eliza McCluskey Memorial Bequest (JKM). The National Health and Medical Research Council of Australia (MT), The Royal Perth Hospital Research Foundation, The University of Western Australia and Ethicon for the supply of microsutures. The people who have been contributors to this group's work over the last 15 
and $\mathrm{S}$ Meagher. In addition, technical support has come from M Holmes, A Cockson, M Thompson and many others. Finally we would like to thank Rita Bonjour for her expert secretarial assistance.

\section{REFERENCES}

1. Barid RN, Abbott WM (1977) Vein grafts: A historical perspective. Am J Surg 134: 293-296

2. Samuels RM (1987) BSc Honours Thesis: Longterm tissue changes in the $1 \mathrm{~mm}$ polytetrafluoroethylene (Gore-Tex) microvascular grafts. University of Western Australia, Department of Anatomy and Human Biology

3. Lidman DH, Faibisoff B, Daniel RK (1980) Expanded polytetrafluorethylene as a microvascular graft: An experimental study. J Microsurg 1: 447-456

4. Samuels RM, McGeachie, JK, Prendergast FJ, Storrie EA (1989) Long term changes in 1mm PTFE (Gore-Tex) prosthetic arterial grafts. Microsurgery 10: 274-282

5. Woolf N (1983) Pathology of Atherosclerosis. Ed. Craford T, Butterworth Scientific: London

6. Crawford T (1961) Morphological aspects in the pathogenesis of atherosclerosis. J Athero Res 1:3-25

7. Gerrity (1981) The role of the monocyte in atherogenesis. . Transition of blood borne monocytes into foam cells in fatty lesions. Am J Pathol 103: 181-190

8. Roessner A, Schmitz G, Sorg C (1987) What's new in the pathology of atherosclerosis? Path Res Pract 182: 694-698

9. Prendergast FJ, McGeachie JK, Edis RH, Allbrook DB (1977) Whole muscle reimplantation with microneurovascular anastomoses. Annl R Col Surg (Eng) 59: 393-400

10. Prendergast FJ, McGeachie JK, Fabre JW, Winearls CG, Morris PJ (1979) Vein allografts for arterial replacement in rats. Transplantation 27:49-54

11. McGeachie JK, Prendergast FJ, Morris PJ (1983) Vein grafts of arterial repair: an experimental study of the histological development of the intima. Annl R Col Surg (Eng) 65:85-89.

12. Dilley RJ, McGeachie JK, Prendergast FJ (1983) Experimental vein grafts in the rat: reendothelialization and permeability to albumin. Br J Surg 70:7-12

13. Tennant M, Dilley RJ, McGeachie JK, Prendergast FJ (1990) Histogenesis of arterial intimal hyperplasia and atherosclerosis. Aust N Z Surg 60:79-85

14. Campbell PA, McGeachie JK, Prendergast FJ (1981) Vein grafts for arterial repair: their success and reasons for failure. Annls R Col Surg (Eng) 63257-260

15. Clowes AW Kirkman TR Reidy MA (1986) Mechanism of arterial graft healing. Rapid transmural capillary ingrowth provides a source of intimal endothelium and smooth muscle in porous PTFE prosthess. Am J Pathol 123: 120-130

16. Dilley RJ, McGeachie JK and Prendergast (1986) A morphometric study of vein graft intimal hyperplasia. Plastic ReconSur 77:451-454

17. Dilley RJ, McGeachie JK, Prendergast FJ (1987) A review of the proliferate behaviour, morphology and phenotypes of vascular smooth muscle. Athero 63:99-107

18. Dilley RJ, McGeachie JK, Prendergast FJ (1988) A review of the histologic changes in vein to artery grafts: with particular reference to intimal hyperplasia Arch Surg 123:691696

19. Fuchs JCA, Mitchener JS, Hagen PO (1978) Postoperative changes in autologous vein grafts. Ann Surg 188: 1-15

20. Brody WD, Kosek JQAngell WW (1972) Changes in vein grafts following aortocoronary bypass induced by pressure and ischemia Cariovasc Surg. 64: 847-853

21. Suggs WD, Henriques HF, Depalma RG (1988) Vein cuff interposition prevents juxtaanastomotic neointimal hyperplasia. Ann Surg 207: 717-723

22. Unni KK, Kottke BA. Titus Jl, Frye RL, Wallace RB, Brown AL (1974) Pathologic changes in aortocoronary saphenous vein grafts. Am J Cardiol 34:526-532

23. Sottiurai VS, Yao JST, Flinn WR, BatsonRC (1983) Intimal hyperplasia and neointima: An ultrastructural analysis of thrombosed grafts in humans. Surg 93: 809-817

24. Spray TL, Roberts WC (1977) Changes in saphenous veins used as autocoronary bypass grafts. Am Heart J 94: 500-516

25. Campeau L, Enjalbert M, Lesparance J, Vasislic C, Grondin CM, Bourassa MG (1983) Atherosclerosis and late closure of aortocoronary saphenous vein grafts; sequential angiographic studies at 2 weeks, 1 year 5-7 years, and 10-12 years after surgery. Circ 68 (II): 1-7

26. Dilley RJ, McGeachie JK, Tennant M (1991) The role of cell proliferation and migration in vein to artery graft intimal hyperplasia in rats. Cell Tiss Res (submitted)

27. Dilley RJ, McGeachie JK, Tennant M (1991) A quantitative analysis of smooth muscle cell ultrastructure in rat autogenous vein grafts. Cell Tiss Res (submitted)

28. Tennant M, McGeachie JK (1991) Permanent structural alterations to endothelial cells in vein to artery grafts: A quantitative electron microscopic study. Cell Tiss Res (submitted)

29. Tennant M and McGeachie JK (1991a) Platelet-derived growth factor and its role in atherogenesis: a brief review Aust NZ J Surg (In Press)

30. Nilsson J (1986) Growth factors and the pathogenesis of atherosclerosis. Athero 62: 185-199

31. Nilsson J, Sjolund M, Palmberg L, Thyberg J, Heldin CH (1985) Arterial smooth muscle cells in primary culture produce PDGF-like protein. Proc Nat Acad Sci USA 82: $4418-4422$

32. Sjolund M, Sejersen T, Heldin CH, Thyberg J (1988) Arterial smooth muscle cells express platelet-derived growth factor (PDGF) A chain mRNA, secrete a PDGF-like mitogen, and binds exogenous PDGF in a phenotype-and growth statedependant manner. J Cell Biol 106: 403-413

33. Wilcox JN, Smith KM, Schwartz SW, Gordon D (1988) Platelet derived growth factor mRNA detection in human atherosclerotic plaques by in-situ hybridization. J Clin Invest 82: $1134-1143$

34. Ross R (1986) The pathogenesis of atherosclerosis - an update. N Eng J Med 314:488-499

35. McGeachie JK, Campbell PA, Prendergast FJ (1981) Vein to artery grafts: a quantitative study of revascularisation by vasa vasorum and its relationship to intimal hyperplasia. Annls Surg 194: 100-107

36. McGeachie JK, Meagher S, Prendergast FJ (1989) Vein to artery grafts: the long term development ${ }^{\mathrm{v}}$ of neo-intimal hyperplasia and its relationship to vasa vasorum and sympa- 
thetic reinnervation. Aust NZ J Surg 59:59-65

37. Adcock OT, Adcock OLD, Wheeler JR, Gregory RT, Snyder SO, Gayle G (1984) Optimal techniques for harvesting and preparation of reverse autogenous vein grafts for use as arterial substitutes; A review. Surg 96:886-893.

38. Waris T, Lofstedt T, Partanen S, Smitten KV (1984) Innervation of syngeneic vein grafts in the rat. J Surg Res 37:472478.

39 Meagher S, McGeachie JK, Prendergast FJ (1984) Vein to artery grafts: an experimental study of reinnervation of the graft wall. Annls Surg 200:153-158.

40. Meagher S, McGeachie JK, Prendergast FJ (1987) Vein to artery grafts: a study of reinnervation in relation to neointimal hyperplasia. Aust N Z Surg 57:671-677

41. Zimmerman M, McGeachie JK (1985) The effect of nicotine on aortic endothelial cell turnover: an autoradiographic stud. Athero 58:39-47

42. Zimmerman M and McGeachie JK (1990) The effects of nicotine on arterial endothelial cell turnover and ultrastructure. Proceedings of the Symposium on Tobacco Smoking and Atherosclerosis: Pathogenesis and Cellular Mechanisms. Adv Exp Med Biol 273: 79-88

43. Zimmerman M, McGeachie JK (1986) Quantitation of the relationship between aortic endothelial intracellular cleft morphology and permeability to albumin. Athero 59:277-282

44. Zimmerman M, McGeachie JK (1986) An autoradiographic technique for en-face preparations of aortic endothelium. J Pathol 150:65-68

45. Zimmerman M, McGeachie JK( 1987) The effect of nicotine on aortic endothelium: a quantitative ultrastructural study. Athero 63:33-41

46. Samuels RM, McGeachie^ ${ }^{\wedge K}$, Prendergast FJ, Storrie AE (1989) Nicotine increases permeability of regenerative vein graft endothelium - A quantitative study. J Microsurg (submitted)

47. Lipid Research Clinics Program (1984) The Lipid Research Clinics Coronary Primary Prevention Trial Results: I. Reduction in the incedence of coronary artery disease, JAMA 251:251-264.

48. Nerem R.M., Shaw G.M., Hostetler J.R., Vasko J.S. (1978) Velocity distubution and intimal proliferation in autologous vein grafts in dogs. Circ. Res. 42: 792-801

49. Landymore R.., Kinley C.E., Cameron C.A. (1985) Intimal hyperplasia in autogenous vein grafts used for arterial bypass: a cannine model. Cardiovasc. Res. 17:589-592

50. Dobrin P.B., Littooy F.N., Golan J., Blackeman B., Farced J. (1988) Mechanical and histological changes in canine vein grafts. J. Surg. Res. 44:259-265

51. McGeachie JK, Campbell PA, Simpson S, Prendergast FJ (1982) Arterial vasa vasorum: a quantitative study in the rat. JAnat 134:193-197

52. Tennant M, McGeachie JK (1990) A computerised morphometric technique for the analysis of intimal hyperplasia. $\mathrm{J}$ Anat In press

53. Tennant M, McGeachie JK (1990) Blood vessel structure and function: A brief update on recent advances. Aust NZ J Surg 60:747-753

Adrressfor correspondence:

Dr. John McGeachine, Department of Anatomy and Human Biology, The University of Western Australia, Nedlands, W.A. 6009, Australia. 